\title{
Population Data on Finland 1900-1983
}

\section{Resident population on 31 December}

\begin{tabular}{|c|c|c|c|c|c|}
\hline & & Urban mu & ities & Rural mu & ities \\
\hline & Whole country & number & $\%$ & number & $\%$ \\
\hline 1900 & 2655900 & 333300 & 12.5 & 2322600 & 87.5 \\
\hline 1910 & 2943400 & 432200 & 14.7 & 2511200 & 85.3 \\
\hline 1920 & 3147600 & 507400 & 16.1 & 2640200 & 83.9 \\
\hline 1930 & 3462700 & 715000 & 20.6 & 2747700 & 79.4 \\
\hline 1940 & 3695600 & 991700 & 26.8 & 2703900 & 73.2 \\
\hline 1950 & 4029800 & 1302400 & 32.3 & 2727400 & 67.7 \\
\hline 1960 & 4446200 & 1707000 & 38.4 & 2739200 & 61.6 \\
\hline 1970 & 4598300 & 2340300 & 50.9 & 2258000 & 49.1 \\
\hline 1980 & 4787800 & 2865100 & 59.8 & 1922700 & 40.2 \\
\hline 1981 & 4812000 & 2881000 & 59.9 & 1931000 & 39.9 \\
\hline 1982 & 4841700 & 2897100 & 59.8 & 1944600 & 40.2 \\
\hline $1983^{*}$ & 4872000 & & .. & & \\
\hline
\end{tabular}

Age Structure

\begin{tabular}{|c|c|c|c|c|c|c|c|c|c|}
\hline & \multicolumn{3}{|c|}{ Whole population } & \multicolumn{3}{|c|}{ Men } & \multicolumn{3}{|c|}{ Women } \\
\hline & $0-14$ & $15-64$ & $65-$ & $0-14$ & $15-64$ & $65-$ & $0-14$ & $15-64$ & $65-$ \\
\hline & $\%$ & $\%$ & $\%$ & $\%$ & $\%$ & $\%$ & $\%$ & $\%$ & $\%$ \\
\hline 1900 & 35.0 & 59.6 & 5.4 & 35.9 & 59.4 & 4.7 & 34.3 & 59.7 & 6.0 \\
\hline 1910 & 35.6 & 58.6 & 5.8 & 36.7 & 58.3 & 5.0 & 34.6 & 59.0 & 6.4 \\
\hline 1920 & 33.4 & 60.7 & 5.9 & 34.8 & 60.0 & 5.2 & 32.0 & 61.3 & 6.7 \\
\hline 1930 & 29.4 & 64.3 & 6.3 & 30.6 & 64.1 & 5.3 & 28.3 & 64.5 & 7.2 \\
\hline 1940 & 26.9 & 66.7 & 6.4 & 28.2 & 66.5 & 5.3 & 25.7 & 66.9 & 7.4 \\
\hline 1950 & 30.0 & 63.3 & 6.7 & 32.0 & 62.8 & 5.2 & 28.1 & 63.9 & 8.0 \\
\hline 1960 & 30.1 & 62.4 & 7.4 & 31.9 & 62.3 & 5.7 & 28.5 & 62.5 & 8.9 \\
\hline 1970 & 24.4 & 66.3 & 9.3 & 25.7 & 67.1 & 7.2 & 23.0 & 65.7 & 11.3 \\
\hline 1980 & 20.2 & 67.7 & 12.0 & 21.4 & 69.6 & 9.0 & 19.2 & 65.9 & 14.9 \\
\hline 1981 & 19.9 & 67.9 & 12.2 & 21.0 & 70.0 & 9.0 & 18.8 & 66.0 & 15.2 \\
\hline 1982 & 19.7 & 68.0 & 12.3 & 20.8 & 70.2 & 9.0 & 18.6 & 66.0 & 15.4 \\
\hline
\end{tabular}

Live births

$\begin{array}{lll}1900-10 & 90293 & 32.4 \\ 1911-20 & 83045 & 27.0 \\ 1921-30 & 78184 & 23.6 \\ 1931-40 & 70584 & 19.7 \\ 1941-50 & 92613 & 24.3 \\ 1951-60 & 88025 & 20.7\end{array}$

$1961-70$
$1971-80$
1980
1981
1982

Per 1000

Number of mean population

76466

62789

63064

63469

66245 
Age specific fertility rate

Per 1000 women

Total

fertility

$\begin{array}{lcrrrrrrr} & 15-19 & 20-24 & 25-29 & 30-34 & 35-39 & 40-44 & 45-49 & \text { per woman } \\ 1901-10 & 17.6 & 157.8 & 213.0 & 236.9 & 191.0 & 114.4 & 18.2 & 4.68 \\ 1911-20 & 14.9 & 122.8 & 181.4 & 181.9 & 155.2 & 92.9 & 14.0 & 3.81 \\ 1921-30 & 14.2 & 110.0 & 156.9 & 143.8 & 116.8 & 67.4 & 10.5 & 3.10 \\ 1931-40 & 14.4 & 96.5 & 126.2 & 108.9 & 82.8 & 43.5 & 5.9 & 2.39 \\ 1941-45 & 11.3 & 105.2 & 144.9 & 124.3 & 88.4 & 41.8 & 5.4 & 2.60 \\ 1946-50 & 25.7 & 161.9 & 189.4 & 147.5 & 100.5 & 43.3 & 5.0 & 3.37 \\ 1951-55 & 27.2 & 157.6 & 165.8 & 125.0 & 81.0 & 35.1 & 3.9 & 2.98 \\ 1956-60 & 29.3 & 161.4 & 159.6 & 108.1 & 67.5 & 27.5 & 2.8 & 2.78 \\ 1961-65 & 30.7 & 156.7 & 156.0 & 98.8 & 55.7 & 22.5 & 2.2 & 2.61 \\ 1966-70 & 34.7 & 131.9 & 125.9 & 76.5 & 39.7 & 13.7 & 1.4 & 2.21 \\ 1971-75 & 27.9 & 104.3 & 106.6 & 55.8 & 23.3 & 6.1 & 0.5 & 1.62 \\ 1976-80 & 22.0 & 96.8 & 114.6 & 67.5 & 26.4 & 6.0 & 0.4 & 1.67 \\ 1980 & 18.9 & 91.5 & 114.6 & 68.0 & 27.1 & 6.4 & 0.3 & 1.64 \\ 1981 & 16.9 & 88.7 & 118.3 & 69.5 & 29.8 & 6.1 & 0.4 & 1.65 \\ 1982 & 16.9 & 90.9 & 124.4 & 73.7 & 30.9 & 6.9 & 0.4 & . .\end{array}$

Gross and Net Reproduction Rate

Gross Reproduction

Rate

1901-10

1911-20

1921-30

1931-35

1936-40

1941-45

1946-50

1951-55

1956-60

1961-65

1966-70

1971-75

1976-80

1980

1981

1982
2.278

1.849

1.504

1.167

1.162

1.262

1.637

1.452

1.357

1.276

1.035

0.790

0.797

0.796

0.806

0.835
Net Reproduction

Rate

0.958

0.962

1.048

1.469

1.373

1.301

1.236

1.009

0.770

0.814

0.779

0.795

Illegitimate live births

$$
\begin{array}{cc}
\text { Number } & \begin{array}{c}
\text { Per cent } \\
\text { of all live } \\
\text { births }
\end{array}
\end{array}
$$

$\begin{array}{lll}1901-10 & 6120 & 6.8 \\ 1911-20 & 6573 & 6.8 \\ 1921-30 & 6606 & 8.4 \\ 1931-40 & 5346 & 7.6 \\ 1941-50 & 5629 & 6.1\end{array}$

Number

$1951-60$
$1961-70$
$1971-80$
1980
1981
1982

Per cent of all live births

4.3
4.7
9.8
13.1
13.3
8.9


Abortions

\begin{tabular}{cccccc} 
& \multicolumn{2}{c}{$\begin{array}{c}\text { Per } 100 \\
\text { live birth }\end{array}$} & & $\begin{array}{r}\text { Per } 100 \\
\text { live birth }\end{array}$ \\
1970 & 14757 & 22.9 & 1977 & 17772 & 27.1 \\
1071 & 20622 & 33.8 & 1978 & 16928 & 26.4 \\
1972 & 22146 & 37.5 & 1979 & 15849 & 25.1 \\
1973 & 23362 & 41.1 & 1980 & 15037 & 23.8 \\
1974 & 22846 & 36.5 & $1982^{*}$ & 13861 & 22.3 \\
1975 & 21547 & 32.8 & & & 20.9 \\
1976 & 19818 & 29.6 & & & 13
\end{tabular}

Marriages

$\begin{array}{ccc} & \text { Number } & \begin{array}{c}\text { Per 1 000 } \\ \text { of mean } \\ \text { population }\end{array} \\ 1901-10 & 18947 & 6.8 \\ 1911-20 & 18922 & 6.2 \\ 1921-30 & 23725 & 7.2 \\ 1931-40 & 28490 & 7.9 \\ 1941-50 & 37367 & 9.5 \\ 1951-60 & 32191 & 7.6 \\ 1961-70 & 37398 & 8.2 \\ 1971-80 & 32575 & 7.0\end{array}$

Number

1980

1981

$1982 *$

29388
Per 1000 of mean population

6.1

6.3

6.3

Median age at first marriage

$\begin{array}{lcc} & \text { Men } & \text { Women } \\ 1901-05 & 26.1 & 23.5 \\ 1906-10 & 26.2 & 23.6 \\ 1911-15 & 26.4 & 23.7 \\ 1916-20 & 27.0 & 24.0 \\ 1921-25 & 26.9 & 24.0 \\ 1926-30 & 26.6 & 23.9 \\ 1931-35 & 27.1 & 24.4 \\ 1936-40 & 27.6 & 24.7 \\ 1941-45 & 27.6 & 24.3\end{array}$

$1946-50$
$1951-55$
$1956-60$
$1961-65$
$1966-70$
$1971-75$
$1976-80$
1980
1981
1982

Men

Women

26.1

23.7

24.9

23.2

24.6

24.1

22.8

22.3

23.6

22.2

24.0

22.7

25.2

23.3

25.6

23.7

23.8

25.8

26.8

24.8

\section{Divorces}

$$
\begin{aligned}
& 1951-60 \\
& 1961-70 \\
& 1971-75 \\
& 1976-80 \\
& 1980 \\
& 1981
\end{aligned}
$$$$
\text { 1982* }
$$

Number

$$
\begin{array}{r}
3584 \\
4860 \\
8727 \\
10051 \\
9464 \\
9497 \\
9738
\end{array}
$$

Per 1000 of mean population

$$
\begin{aligned}
& 0.84 \\
& 1.06 \\
& 1.87 \\
& 2.12 \\
& 1.98 \\
& 1.97 \\
& 2.02
\end{aligned}
$$


Families with children under 18 years of age by number of children (per cent)

Married couples with children*

$\begin{array}{rrrrrr} & 1 & 2 & 3 & 4+ & \text { Number } \\ 1960 & 34.4 & 30.7 & 17.5 & 17.4 & 601542 \\ 1970 & 40.2 & 33.9 & 15.5 & 10.4 & 602076 \\ 1975 & 44.9 & 37.0 & 12.6 & 5.5 & 593346 \\ 1978 & 44.9 & 39.8 & 11.5 & 3.8 & 595944 \\ 1980 & 45.1 & 40.8 & 11.0 & 3.1 & 590655\end{array}$

Mothers with children

$\begin{array}{cccccc} & 1 & 2 & 3 & 4+ & \text { Number } \\ 1960 & 61.1 & 23.0 & 9.2 & 6.7 & 67381 \\ 1970 & 60.7 & 23.8 & 9.5 & 6.0 & 66303 \\ 1975 & 62.4 & 25.7 & 8.3 & 3.6 & 72359 \\ 1978 & 66.2 & 25.2 & 6.5 & 2.1 & 90292 \\ 1980 & 68.0 & 25.1 & 5.5 & 1.4 & 90746\end{array}$

Fathers with children

$\begin{array}{rccccc} & 1 & 2 & 3 & 4+ & \text { Number } \\ 1960 & 56.7 & 24.8 & 10.3 & 8.2 & 9123 \\ 1970 & 61.1 & 24.3 & 9.0 & 5.6 & 8656 \\ 1975 & 64.0 & 24.6 & 8.4 & 3.0 & 10386 \\ 1978 & 68.7 & 23.9 & 5.6 & 1.8 & 10909 \\ 1980 & 71.6 & 22.8 & 4.6 & 1.0 & 11048\end{array}$

* incl. not-married couples with children under 18 years

Families with children under 18 years of age by type of family

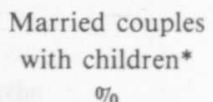

1960

1970

1975

1978

1980

Mothers
with childre
$\%$
10.0
9.8
10.7
13.0
13.1

Fathers

with children

$\%$

1.3

1.3

1.5

1.6

1.6
Number

678046

677035

676091

697145

692449

* incl. not-married couples with children under 18 years 


$\begin{array}{lccc}\text { Deaths } & \text { Number } & \begin{array}{c}\text { Per } 1000 \\ \text { of mean } \\ \text { population }\end{array} & \begin{array}{c}\text { Infant mortality } \\ \text { per } 1000 \text { live } \\ \text { births }\end{array} \\ 1901-10 & 52099 & 18.7 & 123.8 \\ 1911-20 & 58284 & 19.0 & 111.8 \\ 1921-30 & 49573 & 14.9 & 91.9 \\ 1931-40 & 50222 & 14.0 & 72.0 \\ 1941-50 & 51838 & 13.6 & 56.0 \\ 1951-60 & 39381 & 9.3 & 28.6 \\ 1961-70 & 43494 & 9.5 & 16.7 \\ 1971-80 & 44243 & 9.4 & 11.3 \\ 1980 & 44398 & 9.3 & 7.6 \\ 1981 & 44404 & 9.3 & 6.5 \\ 1982^{*} & 43427 & 9.2 & \ldots\end{array}$

Mean expectation of life at birth

$\begin{array}{lcc} & \text { Men } & \text { Women } \\ 1911-20^{1} & 43.4 & 49.1 \\ 1921-30 & 50.7 & 55.1 \\ 1931-40^{2} & 54.5 & 59.6 \\ 1941-45^{2} & 54.6 & 61.1 \\ 1946-50 & 58.6 & 65.8 \\ 1951-55 & 63.4 & 69.8 \\ 1956-60 & 64.9 & 71.6 \\ 1961-65 & 65.4 & 72.6 \\ 1966-70 & 65.9 & 73.6\end{array}$

$\begin{array}{lcc} & \text { Men } & \text { Women } \\ 1971-75 & 66.7 & 75.2 \\ 1976-80 & 68.4 & 76.9 \\ 1980 & 69.2 & 77.6 \\ 1981 & 69.5 & 77.8\end{array}$

1 Including deaths due to war operations.

2 Excluding deaths due to war operations.

Ecxess of births over deaths

Per 1000

Number

of mean

population

$\begin{array}{rrr}1901-10 & 38194 & 13.7 \\ 1911-20 & 24760 & 8.1 \\ 1921-30 & 28611 & 8.7 \\ 1931-40 & 20354 & 5.7 \\ 1941-50 & 44272 & 10.7 \\ 1951-60 & 48643 & 11.4\end{array}$

International migration
Number

$1961-70$
$1971-75$
$1976-80$
1980
1981
$1982^{*}$

32223

16631

20460

18666

19065

22818
Per 1000 of mean population

7.2

4.6

4.3

3.9

4.0

4.7

$$
\begin{array}{cc}
\begin{array}{c}
\text { Emigrants who } \\
\text { have obtained } 1000 \\
\text { of mean }
\end{array} \\
\text { a passport } & \text { population }
\end{array}
$$

$\begin{array}{rrr}1901-10 & 150832 & 5.4 \\ 1911-20 & 67346 & 2.2 \\ 1921-30 & 58559 & 1.8 \\ 1931-40 & 8844 & 0.2\end{array}$

$\begin{array}{lll}1941-50 & -41000 & 1.1 \\ 1951-60 & -70032 & 1.5 \\ 1961-70 & -177626 & 3.9 \\ 1971-75 & +9489 & 2.0 \\ 1980 & -1198 & 0.3 \\ 1981 & +5729 & 1.2 \\ 1982^{*} & +7035 & 1.5\end{array}$




\section{Internal migration}

$\begin{array}{lccccc} & \text { Number }{ }^{1} & \begin{array}{c}\text { Per cent } \\ \text { of mean } \\ \text { population }\end{array} & & \text { Number } & \begin{array}{c}\text { Per cent } \\ \text { of mean } \\ \text { population }\end{array} \\ 1901-10 & 74784 & 2.7 & 1961-70 & 219330 & 4.8 \\ 1911-20 & 85111 & 2.8 & 1971-75 & 233610 & 5.0 \\ 1921-30 & 79248 & 2.4 & 1976-80 & 193527 & 4.1 \\ 1931-39 & 136470 & 3.8 & 1980 & 197626 & 4.2 \\ 1941-50 & 132778 & 3.5 & 1981 & 193847 & 4.0 \\ 1951-60 & 172098 & 4.0 & 1982^{*} & 193221 & 4.0\end{array}$

1 Average in-migration to rural and urban municipalities

Economically active population by industry

$\begin{array}{lllll}1950 & 1960 & 1970 & 1975 & 1980\end{array}$

Agriculture and forestry, hunting and fishing

Industry etc.

Construction

Commerce

Transport and communications

Services

Unknown

\begin{tabular}{rrrrr}
45.8 & 35.5 & 20.3 & 15.0 & 12.6 \\
20.8 & 21.6 & 25.9 & 27.2 & 26.3 \\
6.3 & 8.7 & 8.3 & 8.5 & 7.1 \\
9.5 & 13.6 & 18.9 & 19.3 & 19.2 \\
5.4 & 6.3 & 7.1 & 7.6 & 7.9 \\
10.8 & 14.0 & 18.1 & 20.9 & 24.8 \\
1.4 & 0.3 & 1.4 & 1.5 & 2.1 \\
\hline 100.0 & 100.0 & 100.0 & 100.0 & 100.0
\end{tabular}

\section{Females in labor force}

The proportion of females in labor force (per cent)

$\begin{array}{ll}1960-64 & 44.0 \\ 1965-69 & 43.3 \\ 1970-74 & 45.3 \\ 1975 & 46.5 \\ 1980 & 47.1 \\ 1981 & 47.4 \\ 1982 & 47.7\end{array}$

Female labor force as a percentage of female population of $15-74$ years

$\begin{array}{ll}1960-64 & 56 \\ 1965-69 & 55 \\ 1970-74 & 56 \\ 1975-79 & 57 \\ 1980 & 59 \\ 1981 & 60 \\ 1982 & 62\end{array}$

